\title{
Aranguren y el papel del intelectual *
}

\author{
IGNACIO SOTELO
}

En muy diferentes escritos - al fin y al cabo, se piensa en las coordenadas del tiempo en que nos ha tocado vivir- José Luis L. Aranguren se ha ocupado de la relación del intelectual con la política, cuestión a la que ha aportado atisbos y enfoques tan originales como esclarecedores, de modo que ya vale la pena resumir lo que ha pensado sobre el tema. Además, su propia obra y sus múltiples actividades, como profesor, publicista y conferenciante incansable, son de tal calibre y enjundia que en base a ellas cabe estudiar de modo paradigmático la influencia del intelectual sobre una España que me permitirá el lector que califique, con la mayor moderación y prudencia, pese a las enormes diferencias, por lo demás obvias, entre el franquismo y el régimen actual, de hosca y bastante difícil en todo momento!

Este artículo consta de tres partes: 1 . Una breve exposición de los aportes de Aranguren al tema. 2. Una segunda que trata de desentrañar el tipo de relación que uno de los intelectuales más destacados ha tenido con la sociedad española en estos últimos cincuenta años, caminando en un doble sentido, desde la obra, para esclarecer su impacto real sobre la sociedad española; y desde ésta hacia al intelectual, interesados en mostrar los condicionamientos sociales - se piensa siempre en un contexto social y como reacción a élque configuran su pensamiento. 3. En fin, y a manera de conclusión provisional, algunas observaciones críticas a la tesis de Aranguren de que el intelectual debe permancecr alcjado de la órbita del poder y, consecuentemente, de la política concreta.

\section{LAS RELACIONES ENTRE EL INTELECTUAL Y LA POLÍTICA SEGÚN ARANGUREN}

Voy a intentar condensar al máximo, procurando, eso sí, no traicionar demasiado, el tratamiento que Aranguren ha dado a las relaciones entre el intelcctual y la política. Es cuestión en la que ha incidido en muy diversas publicaciones, no sólo porque dominó en su tiempo - los europeos de su generación han

* Bajo el título de «Eł moralista frente al político», el autor publicó una primera versión de este texto en el número 7 de Isegoría (abril 1993), prácticamente agotado en la actualidad, de donde lo reproducimos por expreso deseo suyo.

' Hace cuarenta años ya caracterizaba Aranguren a «la vida intelectual española [de] hosca, agria, banderiza y no siempre verdaderam. (ABC, 19 de octubre de 1953). Hoy seguro que no lo haría de forma muy diferente. 
sido prolíficos al respecto-, sino porque conlleva una indudable dimensión personal: como Ortega en su momento, Aranguren en el suyo ha sido, antes que filósofo, intelectual; o si se quiere con mayor precisión, filósofo en cuanto intelectual, o intelectual en cuanto filósofo.

A juzgar por sus comienzos, hubiera cabido muy bien que hubiera cuajado un filósofo, digamos «puro» -denominación a la que, muy significativamente, Aranguren suele referirse con una buena carga de ironía-, preocupado por alguno de los problemas centrales de la filosofía, sin haber rozado, ni de lejos, el rol del intelectual, por así decir, a la manera de otro de sus maestros, Xavier Zubiri. Su primera etapa hacía barruntar un «filósofo de la religión» ${ }^{2}$, rara avis en nuestro medio, que tanto hubiéramos necesitado después de que la temprana muerte de Ángel Álvarez de Miranda malograra la aparición en España de un verdadero «historiador de las religiones».

Los primeros ensayos recogidos en Crítica y meditación ${ }^{3}$ hubieran permitido también esperar un crítico literario nada común, tal vez hasta descubrir un narrador en ciernes ${ }^{4}$, pero se dejó arrastrar por las circunstancias, y éstas le impusieron otros derroteros. Justamente este responder a la circunstancia de manera circunstancial es lo que hace al intelectual. Aranguren lo confiesa paladinamente: «creo que todo cuanto he escrito en mi vida... ha sido, en el recto, casi orteguiano sentido de la palabra, circunstancial» ${ }^{5}$. Frase que también ha escrito, o hubiera podido escribir en los mismos términos Ortega y, con ambos, todo intelectual que, en cuanto tal, se mantenga en relación directa con la sociedad en la que despliega su actividad reflexiva.

Por lo pronto, al asumir con todas sus consecuencias el papel de sintelectual» queda de manifiesto, explícitamente, su ascendencia orteguiana. Conviene, sin embargo, advertir que Aranguren, pese a haber estudiado filosofía antes de la guerra civil en una facultad en la que dominaba Ortega, no es, por así decir, un orteguiano de origen. Sin pertenecer al estrecho círculo de sus discípulos, suele mencionar entre sus maestros, además de Ortega, a Zubiri, D'Ors, Gaos, García Morente. Muchos maestros significa ninguno en el sentido fuerte de la palabra. Aranguren no es hombre de escuela: no tiene un maestro, ni tampoco discípulos particulares; ha andado siempre por libre y ha enseñado a los demás a hacer lo mismo. Sin embargo, es cabalmente orteguiano, no porque haya desarrollado en particular las ideas del maestro, o le hayan servido de especial orientación a la hora de exponer las suyas - aunque las haya tenido

\footnotetext{
${ }^{2}$ Véase Catolicismo y protestantismo como formas de existencia, El protestantismo y la moral, Zubiri y la religiosidad intelectual.

" José Luis L. Aranguren, Crítica y meditaciôn, Madrid, 1957.

4 Véanse en el libro citado anteriormente, «Todos los hombres somos hermanos» y «Nuestra Señora del Recuerdon.

" José Luis L. Aranguren, Erotismo y liberación de la mujer, Barcelona, 1973, p. 7.
} 
muy presentes, a cuya interpretación ha dedicado incluso algunos ensayos ${ }^{6}-$, sino porque en una España muy diferente de la que vivió Ortega, en un contexto ideológico distinto - la historia no se detiene- y a partir de unas creencias propias $^{7}$-recuérdese la distinción orteguiana entre ideas y creencias- ha cumplido en su tiempo la tarea que en el suyo realizó Ortega: advertir los peligros que nos acechan y señalar los caminos que deberiamos seguir. Es decir, ha cumplido rigurosamente con la doble función, critica y utópica, que, como veremos al fínal de esta breve exposición, Aranguren atribuye al «intelectual».

Se interpone aquí una dificultad que vamos a tratar de obviar, haciendo simple mención de ella. Desde la primera acepción de «intelectual» que se nos ha colado de matute, como aquel que reacciona a una circunstancia, de modo que su pensamiento es circunstancial, no por deficiencia o incapacidad, sino por voluntad propia, perturba bastante tratar por separado, como hemos propuesto al comienzo, lo pensado sobre un tema, en este caso la relación del intelectual con la política, de la circunstancia en que surge este pensamiento. Ahora bien, si en mente mantencmos la conéxión entre pensamiento y circunstancia, se gana mucho en claridad expositiva si, de manera diferenciada, nos ocupamos, en primer lugar, de los logros de su pensamiento y luego, de su génesis social. Cierto que sólo cuando contemos con ambas aproximaciones estaremos en condiciones de obtener una comprensión más acertada del pensamiento de Aranguren; tal vez entonces, incluso, estemos en condiciones de esbozar una crítica interna, acaso también más atinada.

Además, un segundo factor, éste ya interno, favorece esta separación. Pese a que Aranguren haya hecho gala de su «infidelidad» - «la vida es fluencia, cambio, movilidad. Ser fiel a la vida requiere, pues, una cierta "infidelidad", en cuanto lo contrario de fijación; cambiar con la vida, aprendiendo continuamente de ella y de los otros ${ }^{8}$ - en la cuestión que nos ocupa, desde el momento en que opta por cumplir plenamente con la «misión» del intelectual, a comienzos de los cincuenta, hasta el día de hoy - son cuarenta años de lúcido ejercicio del oficio (que entiende, no como profesión, sino como officium, deber) -, ha dado muestra de una fidelidad, me atrevería a decir casi tozudez, en la comprensión del papel del intelectual en relación con la política. Continuidad que ha de sorprender tanto más, si tenemos en cuenta los muchos cambios operados en la España que le ha tocado vivir. En todo caso, presentar el pensamiento de Aranguren en este punto crucial como un todo continuo me parece que no constituye una tergiversación excesiva.

\footnotetext{
- Véase, entre otros, los siguientes ensayos de Aranguren: La ética de Ortega, Ecología y conunicación en el pensamiento de Ortega y Gasset, KRebelión de las masas o advenimiento del hombre masa?

"Yo pertenecía a una típica familia burguesa española, de hondo fervor católico. En esos sentimientos y creencias me formé.» Entrevista con Jorge Mañach, Diario de la Marina, La Habana, 14 de diciembre de 1958.

- José Luis L. Aranguren, Memorias y esperanzas españolas, Madrid, 1969, p. 218.
} 


\subsection{Pensamiento circunstancial: además del cómo, el qué}

Pero entremos ya en materia preguntándonos ¿qué entiende Aranguren por «intelectual»?, concepto equívoco donde los haya, cargado de las más distintas emociones. Hay que empezar por señalar que no lo refiere $\sin$ más a aquel grupo social que hace uso de la inteligencia en su actividad profesional - en rigor, no hay actividad humana que no la necesite- después de haber recibido una preparación especifica, ésta ya sí, según el grado de cualificación, privilegio de unos pocos. Quede, pues, bien claro desde un principio que para Aranguren intelectual no es una categoria sociologica que hace referencia al individuo que ha gozado de una educación universitaria, ejerce una profesión liberal, o ha alcanzado merecido renombre como científico, filosofo o escritor. Para mejor aprehender el contenido propio de esta categoría se hace eco de un texto de Roland Barthes en el que distingue «entre écrivain y écrivant (palabra inventada por él). El escritor en cuanto escritor, el poeta sobre todo... es quien trabaja con palabras, de la misma mancra que el pintor con colores, el escultor con formas, el músico con sonidos. Tampoco le denominaré intelectual si nunca sale del arte o la poesía "puros". (Lo que cada vez es más difícil: quicn no toma posición, la ha tomado ya... a favor del sistema establecido, convirtiéndose, quiera o no, en su servidor.) Si, por el contrario -écrivants también- les importan las "ideas" — no las abstractas, filosóficas o científicas - y no sólo las palabras, lo que dicen además de cómo lo dicen, entonces sí» ${ }^{9}$.

En el amplio género de los cultivadores de la inteligencia, en sus más diversas formas, el intelectual es una «especie particular»: aquel que con su obra, además del cómo, le importa el qué. Ahora bien, de algún modo toda obra de creación consiste en una relación determinada de la forma, el cómo, y la materia, el qué. Lo que califica al intelectual es una comprensión específica del qué. El intelectual no se ocuparía de un qué abstracto, sub specie aeternitatis, sino que parte de su circunstancia y reacciona ante ella, $\mathrm{y}$, por tanto, este qué es cabalmente circunstancial.

Ahora bien, el cjercicio circunstancial de la palabra escrita es, por antonomasia, actividad periodística. El periodista, al comentar los eventos del día, reacciona a diario ante la realidad social de su entorno. Si nos conformásemos con la definición del intelectual como un pensador circunstancial que reacciona ante una circunstancia en cambio permanente, tendríamos que concluir que el periodista configura el modelo ideal de intclcctual. Como es muy difícil asumir esta identificación -que además nada tiene que ver con el pensamiento de Aranguren-, habrá que proseguir con la búsqueda de otros elementos más específicos, no sin antes intercalar una pequeña pausa, para hacer hincapié en la estrecha relación existente entre el intelectual y la prensa.

"José Luis L. Aranguren, El oficio de intelectual y La crítica de la critica, Madrid, 1979, pp. $7-8$. 


\subsection{El intelectual y el periodista}

La aparición de la prensa periódica, y su ulterior evolución, coinciden temporalmente con el surgimiento y posterior desarrollo del intelectual. Si no todos los que escriben en los periódicos son intelectuales, los intelectuales, desde que aparecieron como tipo social, suelen escribir en los periódicos. No en vano, fue un artículo de Zola, precisamente publicado en un periódico, el que se considera acta de nacimiento de esta actividad. La prensa ha sido, no el único, pero sin duda alguna el medio más empleado por el intelectual para comunicar con su público. Ortega, en su Prólogo para Alemanes, no sólo confiesa lo obvio - «Y lo primero que necesito decir de mis libros es que propiamente no son libros. En su mayor parte son mis escritos, lisa, llana y humildemente, artículos publicados en los periódicos de mayor circulación de España» ${ }^{10}$-, sino que explicita por qué, después de haber estudiado en Alemania filosofía en su sentido más técnico y riguroso, "saqué la consecuencia de que yo debía dedicar bastantes años a escribir artículos de periódicos " ${ }^{11}$. Las razones que aduce Ortega me parece que no han perdido vigencia en la España de hoy, aunque, cuando tratemos de la crisis del intelectual en este fin de siglo, habrá que mencionar, como un factor a tener en cuenta, la expansión de otros medios de comunicación, como la radio y la televisión, más hostiles al mensaje propiamente «intelectual».

Pese a que la reacción circunstancial al entorno sea propia de periodistas y de intelectuales, tanto los unos como los otros están muy interesados en marcar la diferencia. Para salir del paso se dice que el periodista informa objetivamente - dejemos de lado lo que esto pueda significar, e incluso si resulta hacedero-, mientras que desde la perspectiva del periodista, el intelectual tan sólo opina. Aunque ambos escriban en los periódicos, la distinción entre información y opinión marcaría claramente los límites que separan al periodista del intelectual.

Recojamos el envite, y sin entrar a dilucidar si cualquier proposición, por muy objetiva que se muestre, pueda ser otra cosa que opinión, pongamos énfasis en el sustrato subjetivo que conlleva toda opinión. Porque, justamente, en este carácter, radicalmente personal, se reconoce el intelectual. El intelectual habla desde su subjetividad, entendida como individualidad intransferible e insobornable - desde su «soledad», al decir de Aranguren-, y justamente este origen es el que sustenta su independencia, que quedaría mediatizada si hablase como representante de un grupo institucionalizado.

El intelectual es independiente, porque no oculta, todo lo contrario, su subjetividad, base real de toda independencia. El periodista, en cambio, a partir de una falsa pretensión de objetividad, simula una no menos falsa independencia

"José Ortega y Gasset, Obras Completas, vol. 8, Madrid, 1983, p. 20.

"Idem,p. 26. 
institucionalizada: de ahí el tono de falsete y hasta la trivialidad que despiden hasta los mejores editoriales. El periodista, obligado a scr objetivo por la cmpresa que le paga, no suele encontrar otro resquicio que huir de los juicios extremos, para colocarse, bien en la opinión mayoritaria de los lectores, bien en un punto intermedio, la más fácil - y la más falsa- forma dc objetividad.

\subsection{Portavoz de la mayoría sin voz}

Ahora bien, desde la subjetividad, escribe también el ensayista, y aunque los mejores intelectuales hayan sido ensayistas consumados - piénsese en Ortega, y en el mismo Aranguren- no cabe identificar sin más al intelectual con el ensayista, género ya con una larga tradición que inventó Montaigne al comienzo de la modernidad, y aunque sin él resulte difícil imaginar al intelectual -al menos en su reducción meramente literaria, cosa que Aranguren no hace; al contrario, en alguna ocasión menciona el Guemica como ejemplo paradigmático de obra «intelectual»-, el intelectual, como ya se ha dicho, es un tipo social mucho más reciente, en rigor, propio de nuestro siglo. Pese a existir abundantes puntos de contacto entre el ensayista y el intelectual, conviene separar ambos conceptos: no todo ensayista es un «intelectual», y hay muchos «intelectuales" que desarrollan otros géneros literarios, o se dedican a la ciencia, como Einstein, o al arte, como Picasso, sin perder por ello su carácter de intelectuales consumados.

El intelectual escribe desde su «soledad», pero ello no basta para caracterizarlo, como le basta al ensayista, sino que, además, «ante todo, sabe escuchar lo que no se ha dicho, oír lo que se siente y, por ello, y tras cllo, puede pronunciar la palabra que muchos buscaban, sin acabar de encontrarla. El intelectual asiste con su propia vida a la existencia no solamente suya, a la existencia de su pueblo. Presta así su voz a los unos, es su portavoz, y procura despertar con su voz la conciencia de los otros, de los enajenados, de los manipulados, de los que, para repetir las palabras orteguianas, no asisten a la existencia, a la suya, que, como ya he dicho, no es nunca sólo suya, que está siempre entretejida con la de los otros... Pensar lo que ellos sienten, y, sin vacilación, comprometidamente, decirlo en alta voz» ${ }^{12}$.

La larga cita contiene algunos elementos, ya privativos del intelectual, que nos permiten, al fin, reconocerlo como una especie particular. El intelectual piensa desde y para su circunstancia - dejemos de lado, si cabe pensar de otra forma; es una de las cuestiones claves de la filosofía contemporánea en que se juega su propia identidad-, acurrucado en su soledad, pero abierto a los otros, hasta el punto que se constituye en "portavoz» de una parte de su gente, aquella que no tienen acceso a la palabra pública, a la vez que es incitador, despertador de la «conciencia» de los más «manipulados» o «ena-

\footnotetext{
${ }^{12}$ José Luis L. Aranguren, Memorias y esperanzas españolas, Madrid, 1969, p. 15.
} 
jenados", leal y férreamente «comprometido» con ellos. A comienzos de los sesenta, Aranguren acuñó una fórmula que no ha dejado de repetir: el intelectual es «solidariamente solitario y solitariamente solidario».

La especificidad del intelectual se revela en ser «portavoz» de la mayoría que no tiene «voz", más aún, cn esta función de despertar la «conciencia» de los más «enajenados» y emanipulados», para ayudarlos, con el esfuerzo de su propia liberación, a que todos consigan ser plenamente libres. El intelectual se configura en la conciencia de que el despliegue de su libertad exige la de los otros. El «compromiso» con la propia libertad impone el «compromiso» con la libertad de los otros.

\subsection{El intelectual como moralista}

Llegados a este punto, conviene sacar dos corolarios de la noción de intelectual que hemos elaborado siguiendo a Aranguren. En primer lugar, hablar en este contexto de «intelectual comprometido" es una redundancia. El «compromiso» con su libertad, que incluye la de los demás, es consustancial con el intelectual. En segundo término, el compromiso con la propia libertad, entendida con y desde la libertad de los otros, es lo que constituye la dimensión moral de lo humano. Si a la dimensión pública se añade la dimensión moral del intelectual, podemos ya identificarlo con un tipo preexistente, que no es el periodista, ni el ensayista, sino el moralista. «Quienes ejercen hoy públicamente el viejo oficio de los moralistas son precisamente los intelectuales, cuya función es la de "constituir la conciencia moral de la sociedad", como "demanda y exigencia, como voz de la porción minoritaria más avanzada disponible y progresiva de la sociedad"" ${ }^{13}$.

Al intelectual lo constituye así esa doble dimensión, ética y pública, inherente a toda idea sustantiva de la libertad. Somos sujetos morales, en cuanto somos libres. El escollo consiste en que mi libertad no es real, sino implica y converge con la de los demás. La dimensión moral de lo humano es así a la vez personal y social. Ello supone algo tan obvio, como a menudo olvidado: las cuestiones éticas sólo pueden plantearse en una "sociedad de hombres libres». De ahí que las dificultades que subyacen en toda ética provengan, en última instancia, de no poder vivir plenamente mi libertad porque me falta la de los demás: no me vivo en libertad, sino en relación con los otros. No cabe experimentar la libertad de manera individual y subjetiva; en mi soledad, no soy libre. La experiencia de la libertad sobrepasa cualquier solipsismo. Sólo con los otros y a través de los otros la vivencia de la libertad toma cuerpo. Ahora bien, innumerables son las formas de opresión y de sumisión que crea una sociedad "realmente existente», de modo que la «comunidad de hombres libres», ideal ético de la realización de la libertad, se revela una ilusión, o si se quiere,

${ }^{13}$ Idem, p. 115. 
formulado de un manera positiva, todo lo mâs una «utopía», entendida como un reto a alcanzar que configura el contenido normativo que permite, al menos, definir el sentido de la acción para que la repute moral: una acción la considero moral si amplía mi libertad, a la vez que la de los demás.

Pues bien, el concepto de sintelectual» que maneja Aranguren termina por confundirse con el individuo cabalmente ético que asume una dimensión pública de su existencia. Me apresuro a decir que una especificación semejante del intelectual sobrepasa con mucho el tipo social que pretende describir, al coincidir con la noción de ciudadano que postuló la modernidad revolucionaria. Como en el juego de las siete y media, en el afán de delimitar un concepto operativo de «intelectual», o me paso, al identificarlo con el moralista, o no llego, al hacerlo coincidir con el periodista o el ensayista. La dimensión pública y moral del individuo libre constituye al ciudadano ideal de una democracia ideal, entendida como la forma de organización política de individuos moralmente libres, capaces de vincular su «voluntad particular» en una misma «voluntad general». Barrunto que el intelectual de Aranguren no es más que el ciudadano, a la vez sujeto ético y político, que esbozó Rousseau.

\subsection{Etica y política}

La identificación del intelectual con el «moralista» y su comprensión como «la conciencia moral de la sociedad» marcan de manera indeleble la relación con la política. Los muchos obstáculos, dificultades y problemas que surgen en esta relación, en buena medida, provienen de que haya que separar, a la vez que vincular, estos dos ámbitos. Por un lado, recalca siempre que tiene ocasión que la misión del intelectual «no es política, es moral»; por otro, es consciente de que la política, en el sentido pleno de la palabra, únicamente puede tener un fundamento ético. «El quehacer político es, debe ser, quehacer moral. La política es una dimensión de la moralm ${ }^{14}$. La política, aparece así, en su sentido más sublime, como realización de la ética, a la vez que, en el sentido más perverso, se muestra justamente su negación.

Aranguren ha dedicado un libro a estudiar la relación de la ćtica con la política ${ }^{15}$. Partiendo del carácter «primario» e «inseparable» de lo «personal» y lo «social» en la ética, la entiende como «una exigencia, una demanda, una actitud y, si se quiere una inquietud también, la inquietud moral, la sed de justicia» ${ }^{16}$, a la vez que propugna una concepción «realista» de la política, tal como la estudia una ciencia «positiva», la llamada «ciencia política», que

14 José Luis L. Aranguren, Ética de la felicidad y otros lenguajes, Madrid, 1988, p. 90.

15 José Luis L. Aranguren, Ética y politica, Madrid, 1963. Al lector curioso no Ie quiero ocultar la recensión que de este libro publiqué en el Boletin Informativo del Seminario de Derecho Político. "Ia Universidad de Salamanca, núm. 29-30, 1964.

is $I d_{t} \cdot$, p. 75 . 
se ocupa, ante todo, de «la estructura y el funcionamiento del poder». Justamente estas dos aproximaciones — «idealista» de la ética y «realista» de la políticaponen ya de manifiesto que si, sin mayor reflexión, ambas se vinculasen en una «ética política», es muy alto el riesgo de que quedase enmascarado lo principal que hay que poner de relieve en esta relación, la «tensión» que necesariamente ha de existir entre el ámbito moral y el político.

Para Aranguren, la relación de la ética con la política es cuestionable de cuatro modos: 1. Separando tajantemente ambas, sin dejar punto de contacto: la ética, cuyo ámbito exclusivo sería el privado, no debe entrometerse en la política, y a la inversa, tampoco la política en la ética. Se afirma a la vez y por scparado un «idealismo ético» y un «realismo político». 2. Condenando la política desde la ética; todo lo político sería en sí mismo «malo», frente a la «bondad" de lo ético-privado. Poner énfasis en la «suciedad» de la política es una actitud muy propia de una parte de la «burguesía cultivada», o en su dimensión revolucionaria, del anarquismo. Las dos primeras tesis coinciden en subrayar la incompatibilidad de la ética con la política y no dejan más opción que elegir una de las dos. 3. La tercera posición supone también la incompatibilidad de la ética y de la política, pero desde la conciencia de que no se puede renunciar a ninguna de las dos; de ahí la vivencia «trágica» de esta relación. «El hombre tiene que ser moral, tiene que ser político y no puede serlo conjuntamentes ${ }^{17}$. Hegel ha encarnado existencial y conceptualmente esta relación strágica» de la ética con la política. 4. Ya no se considera la «incompatibilidad», sino tan sólo la «problematicidad» de esta relación, con lo que se mantiene la «tensión», pero desaparece la dimensión «trágica», reducida a una meramente «dramática». «La relación entre la ética y la política, cn cuanto constitutivamente problemática, sólo puede ser vivida, de un modo genuino, dramáticamente» 18 . En el libro comentado, Aranguren se inclina por esta cuarta posibilidad; con el tiempo, sin embargo, irá recalcando cada vez más la incompatiblidad de la ética con la política concreta, sin llegar por ello a asumir claramente la tercera posición.

Si no son incompatibles la ética y la política, 6 cómo hacer entonces efectiva la relación entre ambas, una vez que ha puesto de manifiesto que resulta muy difícil, si no imposible, influir en la política desde una ética individual o social? Aranguren, siguiendo a Hegel, propugna una inversión de los términos, de consecuencias incalculables: la mayor efectividad se conseguiría, no desde la ética individual o social hacia la política, sino desde la política a la ética. El movimiento efectivo ha de ser de la política a la ética. Inserta así la moral en las estructuras político-sociales objetivas, es decir, en «el plano político, administrativo y técnico» de la realidad social que se conoce como Estado. La acción del Estado, si cumple ciertos requisitos, puede revelarse un instrumento capital de moralización. Frente a las formas liberales de distancia-

Idem, p. 77
Idem, p. 78 . 
miento ético de lo estatal, Aranguren propugna que «la moral no puede ser plenamente realizada al nivel colectivo más que por el Estado. La virtud sola, por muy social que sea, no basta ya para la producción de un orden colectivo juston ${ }^{19}$.

Frente a la amoralidad o maldad intrínseca del Estado, Aranguren, en este punto hegeliano, subraya «un precepto de eticidad positiva del Estado: ha de implantar la justicia, ha de conseguir el bienestar, ha de perseguir, en lo posible, la igualdad, ha de aumentar la ilustración y orientar el tiempo libre y el ocio, ha de asentar la democracia» ${ }^{20}$. Un intervencionismo "público», no exclusivamente estatal, que conlleve una dimensión ética ampliamente aceptada y que se imponga por medios cabalmente democráticos, representa una concepción del socialismo muy digna de ser discutida, sobre todo en un momento en que caídas las concepciones dogmáticas y autoritarias, parece que no habría alternativa al liberalismo.

En el libro Ética y política, al proponer una superación ética y democrática del liberalismo, Aranguren llegó a planteamientos claramente socialistas que no ha desarrollado en las etapas siguientes, en las que se echa en falta el "precepto de eticidad positiva del Estado» que había postulado en la «ética de la aliedad». La «tensión dramática» entre ética y política se mantiene, sin embargo, gracias a la doble acepción que da a la política, en el sentido más sublime, como realización de la ética, a la vez que, en el sentido más perverso, justamente como su negación.

\subsection{Heterodoxia del intelectual}

Esta doble cara de la política conlleva que la actitud del intelectual ante ella tenga que ser necesariamente ambigua, de aceptación y de "compromiso" con el primer significado, a la vez que de separación y de demolición crítica del segundo. En Memorias y esperanzas españolas, libro clave para entender el pensamiento de Aranguren, aclara "en qué sentido me interesa $-\mathrm{y}$ muchola política; y en qué sentido no me interesa nada. Como engagement de convivencia, fundado en una moral social, ninguna otra cosa de tejas abajo me importa más que la política, porque ninguna cosa me importa más que España: España en el mundo, claro está, no cn cl "estado de excepción" que la saca de él. Y no me interesa nada la política como afán de participación en el apartado de poder a través de sus dispositivos. Dispositivos que, sin embargo, me entretiene analizar, como viejos, toscos artefactos totalmente inadecuados a nuestro tiempo... y que, extrañamente, siguen funcionando aunque, a mi juicio, no para bien» ${ }^{21}$.

\footnotetext{
${ }^{19}$ Idem, pp. $267-268$

Idem, pp. 262-263

21 José Luis L. Aranguren, Memorias y esperanzas españolas, Madrid, 1969, p. 157.
} 
En el concepto de política, Aranguren maneja dos significados antagónicos: uno, el clásico, como convivencia en paz y libertad de la comunidad social, del que el intelectual en ningún caso puede desinteresarse - «la participación en la política o gobierno de la polis pertenece a la plenariedad del ser hombre» ${ }^{22}$-; otro, moderno, maquiavélico, de la política, como Poder, con todos sus «dispositivos», que el intelectual debe estudiar y conocer, para mejor criticarlos, pero sin acercarse demasiado a ellos, porque esta intromisión cercenaría su independencia y al tinal quebraría su libertad, y con ella, la de todos los sometidos, de los cuales se ha declarado «portavoz».

Aranguren da por supuesto, algo que es todo menos evidente, que no se podría estar con el Poder, menos aún, ejercerlo, y a la vez servir a la inmensa mayoría de los sin voz, de los «manipulados» y «enajenados». Al contrario, piensa que cumplir con los desheredados, material o espiritualmente, ha de implicar la necesidad de distanciarse de la política, como entramado del Poder, para poder así dirigir todos los dardos contra ella. La izquierda, entendida como reforma radical de lo que es, no podría existir más que como reivindicación moral; toda relación con el Poder sería ya intrínsecamente de derechas. Aranguren asume sin más el prejuicio de que «la izquierda inventa los programas políticos renovadores, pero es la derecha quien los realiza, quien los hace pasar» ${ }^{23}$.

Contrapone dos conceptos de la política, uno de ellos incompatible con la ética, que da cuenta suficiente de la forma en que el «intelectual» debe aproximarse a la política, entendida como convivencia, o distanciarse de la política, entendida como Poder, acepción que incluye todas las formas institucionales de la política, desde los partidos hasta los cargos públicos. De ahí que el intelectual, si lo es de verdad, se distinga por un rasgo que le hace fácilmente perceptible, resultar «incómodo»: «es un aguafiestas, con su manía de estar diciendo siempre "no" a la injusticia" ${ }^{24}$.

La toma de posición frente al Poder y a favor de los que carecen de él - no hace falta señalar el fondo cristiano de esta actitud - convierte al intelectual en un «heterodoxo" de todo lo «establecidow: ideas, instituciones, mores. «Es precisamente en esta lucha contra el conformismo y el marasmo donde cobra todo su sentido la actividad de los intelectuales. Si "conviene que haya herejes" y la auténtica democracia requiere siempre discrepancia, nadie como el intelectual, "hereje moderno" de la sociedad, de toda sociedad —oriental u occidental-, puede desempeñar esta necesaria, aunque tal vez desairada función» ${ }^{25}$. Obsérvese que Aranguren define al intelectual con una categoría eclesiástica, la de hereje, una vez que él mismo en su libro La crisis del cato-

${ }^{22}$ José Luis L. Arangurcn, Ética de la felicidad y otros lenguajes, Madrid, 1988, p. 89.

${ }^{23}$ Conversaciones con José Luis L. Aranguren, Madrid, 1976, p. 179.

${ }^{24}$ José Luis L. Aranguren, Memorias y esperanzas españolas, Madrid, 1969, pp. 115-116.

${ }_{25}$ José Luis L. Aranguren, Ética y política, Madrid, 1963, pp. 306 307. 
licismo, relativizó la contraposición ortodoxia-heterodoxia, llegando a definirse como un "cristiano-católico-heterodoxo» ${ }^{26}$.

A partir de la dimensión moral que le es propia - no olvidemos que el intelectual es el «moralista de nuestro tiempo»- está obligado, si quiere permanenecer fiel a su misión, a ejercer una crítica radical de lo existente, más aún, si sus fucrzas se lo permiten, a trazar alternativas, sin temer, todo lo contrario, que parezcan utópicas. Nos topamos así con la doble función, crítica y utópica, que mencionábamos al comienzo, propias de ese «heterodoxo», denunciador del Poder, en que, según Aranguren, consistiría el intelectual. Se descubre así como el «heterodoxo» que sistemáticamente dice «no» al orden constituido, es decir, a lo que es, desde la visión moral de lo que debe ser. Y como el abismo entre lo que es y lo que debe ser permanece en todo tiempo insalvable, la función del intelectual no perdería nunca actualidad.

\subsection{El intelectual y el ideólogo}

Este carácter de «heterodoxo» que, según Aranguren, define al intelectual tiene, además, la virtud de permitir diferenciarlo del «ideólogo», que cumple con todos los requisitos reseñados del «intelectual», pero que, en última instancia, se diferencia del auténtico por mantener una conexión directa con la política concreta, ora por su filiación a un partido político, ora por ocupar un cargo público, o simplemente, por defender en alguna ocasión posiciones del establishment. Al intelectual «establecido», al servicio de un partido, de un grupo o de una clase, Aranguren prefiere llamarle «ideólogo», lo que no ha de entenderse en un sentido necesariamente peyorativo, ya que si opera de intermediario entre intereses opuestos, o clarifica posiciones, evitando incoherencias y contradicciones, puede ser útil a la comunidad, pero, eso sí, se trata ya de otra especie. A los otros tipos de intelectuales comprometidos en política, con la excepción del intelectual-profeta, Aranguren los rebaja a la categoría de «ideólogos».

Pese a lo escrito en Ética y politica, Aranguren termina por aceptar el supuesto de que la política, en cuanto vinculada al Poder, resulta incompatible con la ética y, por tanto, contrapone, como si fueran antagónicas, la kactitud ética» a la «actitud política». Incompatibilidad de la ética y de la política que, más que el viejo prejuicio burgués, trasluce un trasfondo «anarquista individualista» en el último Aranguren, que con el tiempo va diluyendo los contenidos "socialistas» y «estatistas» de su período de defensa de la «ética de la aliedad».

\footnotetext{
${ }^{26}$ Entrevista con José Jiménez Lozano, Destino, 4 de diciembre de 1971.
} 


\subsection{Razones sociológicas del distanciamiento de la política}

Pero, además de un fundamento filosófico, que habrá aún que desentrañar, el desapego de Aranguren de cualquier intromisión en el ámbito concreto de la política tiene una base sociológica. Se recordará que Aranguren en 1955 consiguió una cátedra de "Ética y Sociología» en la Universidad Central de Madrid, creo que todavía se llamaba así. Al parecer, la vinculación de dos disciplinas tan diversas en una sola cátedra - anteriormente habían sido ocupadas, la de Ética por Manuel García Morente y la de Sociología por Severino Aznar - no tuvo otra causa que ahorrarse una dotación. Tamaña barbaridad - y la llamo así por el motivo subyacente, ya que cabía muy bien que se hubiera llegado a esta decisión por una razón científica o pedagógica, más o menos discutibles - resultó muy provechosa al nuevo catedrático.

Como sabrá el lector, Aranguren fue un niño, luego un muchacho, y al final, un hombre muy aplicado y cumplidor de sus deberes, de modo que, en vez de hacer pasar la ética por sociología, o a la inversa, se esforzó en tratarlas como lo que son, dos disciplinas autónomas. En la filosofía moral ya tenía a sus espaldas una obra considerable, que había culminado con la publicación de la Ética en 1958; en cambio, poco había hecho en sociología, de modo que consideró su deber dedicarse con juvenil entusiasmo a la entonces, al menos en España, todavía joven ciencia.

La apertura de su pensamiento a la sociología, una vez que como intelectual se había abierto a la sociedad, amplió su horizonte, hasta entonces muy ceñido a la filosofía - la de Heidegger le ocupó los años de la posguerra- y a la literatura, en particular a la poesía, desde San Juan de la Cruz a los poetas de su generación, sobre el fondo humanístico que había recibido de su educación con los jesuitas. Pues bien, gracias a arbitrariedad tan típica de nuestra España, Aranguren se abre a la sociología desde la filosofía como en los años treinta lo habían hecho Horkheimer y Adorno en Alemania. En los años sesenta y setenta, Habermas es el ejemplo más característico de esta fusión, tan productiva, del filósofo con el sociólogo.

Una segunda barbaridad - aunque, claro está, no comparable con la anterior, pura anécdota - fue el que le despojaran de su cátedra en 1965, ésta ya sî exclusiva de la España franquista. Cumpliendo con la función moral del intelectual, Aranguren, junto con otros profesores, había encabezado una manifestación estudiantil pacífica al rectorado para reivindicar los derechos y libertades más elementales. Tres profesores fueron expulsados definitivamente y dos con carácter temporal. El intelectual que cumple con su misión de protesta pública paga un precio, tanto más elcvado cuanto más autoritario sea el régimen político al que se enfrente. Al mismo Aranguren, pese a su origen y prestigio, se le pasa la factura. La expulsión de la universidad, como él mismo ha repetido a menudo, ocurre "en el momento oportuno" - «hay que saber ser echado 
a tiempon- y, por paradójico que parezca, le reporta más beneficios que perjuicios, precisamente por verse condenado a la emigración. Su estancia en California en la segunda mitad de los sesenta y comienzos de los setenta - no podía caer en mejor sitio - resultó harto fecunda para una comprensión sociológica del mundo en que vivimos.

Además de una fundamentación filosófica, hay que mencionar una sociológica en el distanciamiento de Aranguren de la acción política directa. En estos años de profesor de sociología elabora la opinión de que los problemas más acuciantes de la sociedad contemporánea no se plantearian en el plano de la acción política institucional y, por tanto, díficilmente cabría encontrar en este campo las soluciones apropiadas. No son «políticas» las cuestiones más esenciales y profundas de nuestra sociedad y, en consecuencia, tampoco "políticas», en el sentido más pedestre, las soluciones pertinentes. Frente a lo que creen los políticos, y los pocos que viven fascinados por la política, no serían políticas, en un sentido estricto, las grandes cuestiones de nuestro tiempo.

En 1969, escribía Aranguren: «mi idea, desde hace mucho tiempo, es que la actual crisis española, más profundamente que una crisis política, es una crisis moral, con lo cual quiero decir que es una crisis consistente en desmoralización. Desmoralización de los vencidos, originada en la impotencia o en la conciencia (más o menos justa o errónea) de la impotencia; desmoralización de los vencedores, cuyo proyecto se limita, desde hace mucho tiempo, a la conservación, a todo trance, del poder; y desmoralización, quizá la más grave de todas, de esa masa neutra que, neutralizada políticamente - lo que quiere decir apoyando de modo pasivo a los detentadores del Poder-, no piensa sino en el aumento de los ingresos y el bienestar ${ }^{27}$. Con una nueva asignación de los «vencedores» y los «vencidos", el texto no ha perdido con el paso del tiempo un ápice de actualidad.

El concepto de «desmoralización» aparece aquí en un sentido ya claramente sociológico y alude a la «metamorfosis de los valores» en las sociedades occidentales, así como a la "anomía» y disolución social que conlleva la llamada «sociedad de consumo», temas de que tanto se ha ocupado la sociología de los años setenta y ochenta y que Aranguren introdujo en la discusión de los problemas nacionales. Se trata, pues, de fenómenos estrictamente sociales que hay que estudiar en esta dimensión con los instrumentos propios de la sociología. En consecuencia, la respuesta a problemas de tal envergadura no es primariamente económica o política, sino que ha de ser social. La autonomía relativa de lo social es el postulado básico de unos años que colocaron a la sociología en la cúspide de las ciencias sociales, frente a la historia, la economía o la ciencia política.

Al tratar de acotar el problema de la sociedad contemporánea a sus elementos decisorios, Aranguren busca la respuesta apropiada en el plano de

\footnotetext{
${ }^{27}$ José Luis L. Aranguren, Memorias y esperanzas españolas, Madrid, 1969, pp. 113-114.
} 
la educación. La «desmoralización de la sociedad» exige como antídoto una revolución en los contenidos y en las formas educativas. "Si "el problema" es un "problema" moral, en el sentido más radical de la palabra, es decir, tocante a los mores y al sistema cultural en que se integran, es obvio que la educación - y el modo de concebirla y llevarla a cabo-cobra una importancia capital» ${ }^{28}$. La «revolución educativa» es el supuesto básico de la «revolución cultural» que pide la «desmoralización» y progresiva disolución anómica de la «sociedad de consumo».

El moralista Aranguren, convertido en sociólogo, se ocupa de la reforma universitaria ${ }^{29}$ - todavía pendiente - y estaba preparando una amplia investigación sobre la educación en España, con financiación extranjera, cuando la pérdida de la cátedra le obliga a emigrar ${ }^{30}$. Consciente de la importancia crucial de «la sociología de la educación» para enfrentarse a la «crisis de nuestro tiempo", amplía el enfoque hasta encajarla en una "sociología de la comunicación", de la que la educación es sólo un capítulo, aunque central. "La educación es la forma fundamental de socialización y, por tanto, de comunicación. Las otras formas de comunicación... pueden estar más desarrolladas tecnológicamente que la comunicación docente pero, en cuanto al contenido, la comunicación pedagógica es el factor principal de integración, de estancamiento o de progreso de país» ${ }^{31}$. Para Aranguren, no son la «estructura económica», como quiere un "marxismo vulgar» hace tiempo interiorizado por la derecha, ni la «estructura política», como en el fondo asume la izquierda activista, las decisivas para encarar la cuestión clave de nuestro tiempo -la "desmoralización» implícita en la «sociedad de consumo"-, sino las distintas formas de «comunicación», entre las que la «educación» ocupa una posición central. «El dilema, según veo las cosas, y para decirlo en pocas palabras, es: comunicación por la propaganda, o comunicación por la educación libre y creadora, moral y cultural» ${ }^{32}$.

Aranguren no sólo desplaza a la política del centro de la problemática contemporánea - rompe con ello, en cierto modo, con su generación, la de los años treinta, la más politizada de la Europa contemporánea- al mostrar que «la raiz de los males» se encuentra en un plano moral que revierte a uno social, «mucho más que en el de la superestructura política», sino que, además, desde una perspectiva meramente sociológica, fundamenta su distanciamiento de los aparatos políticos - partidos e instituciones- por el hecho fundamental de que en las modernas sociedades de masas habrían dejado de servir como instrumentos adecuados. Entre los muchos argumentos de toda

Idem, p. 161.

* José Luis L. Aranguren, «El futuro de la Universidad», Obras, Madrid, 1965, pp. 954-975.

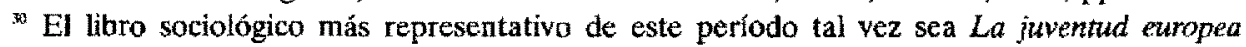
y otras ensayos, Madrid,

"José Luis L. Aranguren, La comunicación humana, Madrid, 1967, p. 158.

\. José Luis L. Aranguren, Memorias y esperanzas españolas, Madrid, 1969, p. 181. 
índole que aporta Aranguren para justificar su apartamiento de la política, el más peregrino es que «la política, por bucna que sea, es siempre una simplificación de la realidad, y el intelectual se debe a la verdad entera» ${ }^{33}$, mientras que, a mi parecer, el más convincente consiste en señalar su poca eficacia para resolver los grandes problemas de la sociedad contemporánea. Durantc el anterior régimen Aranguren se mantuvo al pairo, sin formar parte de los partidos ni de las organizaciones de la oposición, por un montón de razones y de motivos, pero también, sencillamente, porque desconfiaba de su eficacia. «Me parece bien que haya gente en la oposición, pcro no creo mucho en la eficacia de eso ${ }^{34}$. La eficacia política de la acción del intelectual, pertenezca o no a un partido, es cuestión también harto cuestionable, que no vale echar en saco roto.

\section{LA GÉNESIS SOCIAL DEL PENSAMIENTO POLÍTICO DE ARANGUREN}

Dos son las tareas de esta segunda parte. La primera, mostrar de qué forma las consideraciones que Aranguren ha ido haciendo a lo largo de su obra sobre la relación del intelectual con la política - confío en que lo expuesto corresponda en lo esencial a su pensamiento - han sido condicionadas por su circunstancia. La segunda, la manera cómo un intelectual determinado, en este caso Aranguren, haya podido influir sobre la sociedad española. La primera, condicionamientos sociales de un pensamiento, no siendo nada fácil, resulta bastante más hacedera que la segunda, sobre la que, en rigor, nada tengo que decir, como no sean algunas presunciones meramente intuitivas.

Al preguntarse por los condicionamientos sociales del pensamiento de Aranguren, se impone una primera constatación. Cuando en 1977 el régimen franquista, sin traumas ni demasiados aspavientos, desemboca por su natural inercia en el régimen «democrático» que ahora tenemos, el pensamiento de Aranguren ya estaba construido en sus partes principales, tanto en su primera dimensión filosófica-religiosa, como en la posterior, sociológica; también en lo que concierne al tema que nos ocupa. No he comprobado cambios sustanciales debidos a la nueva - quizás no tan nueva - coyuntura política. La circunstancia, como factor a tomar en consideración en la génesis de su pensamiento, es así la franquista.

Hemos llegado a un punto tal, en parte de falsificación y en parte de olvido de nuestra historia inmediata, que puede que no resulte ocioso recordar que Aranguren fue un hombre del franquismo. Por lo pronto, por la generación a que pertenece; cuando estalla la guerra civil tiene veintisiete años; la mayor parte, y la más sustancial de su obra, la publica en los largos años de la dictadura.

${ }_{37}$ Conversaciones con Jose Luis L. Aranguren, Madrid, 1976, p. 104.

* Entrevista con José Luis L. Aranguren, El Ideal Gallego de 27 de octubre de 1973. 
Pero también lo es por origen social, convicciones religiosas, e incluso políticas en los primeros años de la posguerra. El franquismo ha marcado también a los que lo combatieron; y en este sentido, con veinte años de oposición intelectual, Aranguren es también un hombre del franquismo: desde comienzos de los cincuenta fue distanciándose del régimen, cada vez con mayor lucidez y valentía, hasta la ruptura total, tras su expulsión de la universidad en 1965. Durante diez años, hasta la muerte del dictador en 1975, fue, sin duda, el intelectual crítico más escuchado fuera y dentro de España.

La evolución de Aranguren, como la de cualquier individuo, sucede en un proceso histórico determinado, de modo que las posturas que va adoptando en cada momento sólo se entienden dentro del contexto social ante el que reacciona. Respuestas personales que, al adquirir una cierta densidad social, influyen a su vez sobre la situación, modificándola en el sentido querido. Hay que encajar, por tanto, la evolución de Aranguren en la del régimen, que por mucho que predicó la invariabilidad de sus principios, sólo mantuvo uno inmutable: el poder personal indiscutido del «Caudillo». En todos los demás hubo cambios importantes, al principio con enorme lentitud, que se aceleran según se va acercando el final. Desde el comienzo de la guerra civil hasta la muerte del dictador hay que distinguir diferentes etapas con caracteres bastante distintos, y dentro de cada una habría que instalar el pensamicnto correspondiente de Aranguren.

Tampoco se puede plantear la segunda cuestión, la de la influencia del intelectual Aranguren sobre la sociedad española sin instalarla en esta misma periodización, pero, sea cual fuere la que elijamos - yo propondría las siguientes etapas: $1939,1946,1953,1959,1966,1976$ - lo único que me importa resaltar es que la fecha más importante a partir de 1939 no es el 20 de noviembre de 1975. En cambio, a la hora de apreciar la influencia de Aranguren sobre la sociedad española, probablemente esta fecha sí que sea esencial para diferenciar dos etapas con rasgos muy distintos. La mayor influencia de Aranguren se produjo durante el franquismo, sobre todo en su último decenio; en cambio, con la consolidación de la democracia ha ido disminuyendo.

\subsection{Aranguren y la guerra civil}

Aranguren tiene treinta años en 1939, y si, cronológicamente, hubiera podido ser un hombre de la preguerra, de la guerra o de la inmediata posguerra, en rigor, en lo que se refiere a su actividad intelectual y a la reflexión que sobre ella hace, es un hombre de los años cincuenta y sesenta. Ésta es la circunstancia que le configura y a la que responde su pensamiento.

Llama la atención el retraso considerable con que reacciona a su medio, y no porque éste no hubiera sido lo bastante conflictivo desde su más temprana juventud. Necesita explicación el hecho - que insisto, por lo demás sorpren- 
dente - de que se hubiera abstenido de cualquier actividad pública en los años de la República, que durante la guerra no hubiera tomado partido entusiasta por ninguno de los bandos contendientes - perteneciente por origen social y por confesión religiosa al llamado bando «nacional», en el que tuvo la suerte de caer por encontrarse de veraneo en San Sebastián aquel nefasto 18 de julio, no se hizo ni siquiera alférez provisional- y continuó alejado del mundo, pretextando una enfermedad, más imaginaria que real, en los años hoscos de la posguerra.

Aranguren da cuenta de este apartamiento por el poco atractivo que la vida pública española presentó tras la contienda. «Al sentirnos totalmente ajenos al rostro público de la vida española de la época, es normal que nos retrajésemos a la vida privada, la del hogar, la del amor a la mujer, el cariño a los hijos, la fraternidad con los amigos, la consideración filosófico-poética del tiempo en su pasar y en su recuerdo, de la muerte en su lento acercarse; y que nos retrajésemos también a una vida religioso-trascendente, vida unamuniana, pero aserenada, a la búsqueda y encuentro de Dios» ${ }^{35}$. Explicación que suena a racionalización a posteriori, ya que el argumento pudiera ser válido para la posguerra, pero no sirve para explicar un mismo alejamiento del mundo antes y durante la guerra. $Y$ a nadie se le oculta una continuidad muy significativa en su actitud durante estas tres etapas, en sí mismas, tan distintas.

$\mathrm{Ni}$ que decir tiene que este extraño comportamiento puede explicarse a partir de su talante personal, introvertido y tímido; su vocación filosófica -en los años de la República se encierra a estudiar filosofía "pura»-, con un Ortega desencantado de la política que, con su vuelta a la filosofía más técnica y sistemática, pretende recuperar el mucho tiempo perdido con una España desembridada que corre a la catástrofe; o bien, su profunda religiosidad intimista, a la búsqueda del Deus absconditus, todo ello facilitado por un patrimonio familiar que le libra de las inquietudes más perentorias.

Sean cuales fueren las razones de este apartamiento, son mucho más profundas y complejas que la sola hosquedad de la vida española de la posguerra. He consignado las que me resultan más notorias, convencido de que el Aranguren introvertido, profundamente religioso, lector empedernido de libros de filosofía, mística y poesía - su primer libro, largo tiempo inédito, lo dedicó a San Juan de la Cruz-, en fin, el Aranguren recatado y silencioso de su primera etapa configura el trasfondo del intelectual abierto y corrresponsable con la sociedad en la que actúa de los años sesenta y setenta.

Porque por grande que haya sido el cambio entre la etapa de silencio y la pública - casi se podría interpretar como una «conversión», a la que implícitamente alude, cuando se cnorgullece de su «infidelidad»- el despego por la política concreta se muestra una constante. Mucho antes de que en la etapa pública de Aranguren el distanciamiento de la política diaria se justificara filosófica y sociológicamente como una calidad específica del intelectual,

\footnotetext{
"3 José Luis L. Aranguren, Memorias y esperanzas españolas, Madrid, 1969, p. 65.
} 
aquél se alimentaba tanto del «apoliticismo conformista del grupo social» del que procedía, como de la "educación religioso-tradicional» que había recibido, apoliticismo, por lo demás, fuertemente arraigado en las clases altas y medias altas, y no sólo de la sociedad española. En cambio, los intelectuales provenientes de las clases trabajadoras o de los sectores más bajos de las clases medias propendían a una mayor politización.

Con todo, tengo para mi que el marcado apoliticismo de Aranguren, presente a lo largo de toda su vida, hunde sus raíces en el repudio a la politización extrema - y para más inri, polarizada entre fascismo y comunismo- que le tocó vivir en su juventud. Tal vez también aquí haya que buscar la explicación para una omisión que me ha resultado siempre sorprendente en Aranguren: aunque biográficamente la guerra civil parte su vida en un período crucial -entre los veintisiete y los treinta años - falta en su obra una reflexión significativa sobre este acontecimiento, sin duda uno de los decisivos de la España contemporánea. Cierto que en los años cuarenta, cincuenta y hasta bien entrados los sesenta resultaba impensable una meditación pública realizada en el interior sobre tamaño acontecimiento, y luego tal vez ya inoportuna. Pero esta carencia -que subrayo porque en ningún caso es un rasgo individual- me parece muy sintomática: hemos dado la espalda a la guerra civil, sin hurgar en lo que de verdad ha significado como punto de partida de la España de nuestro tiempo. $Y$ esto nos marca.

Sé bien que este sociologismo elemental es bastante alicorto, quizás con un alcance mínimo en el caso de Aranguren, pero lo que me importa consignar es que la experiencia vital de Aranguren antes, durante y después de la guerra, así como el desencanto de la política que vive la débil burguesía ilustrada en la España de aquellos lustros, constituyen el telón de fondo desde el que hay que leer al Aranguren de su etapa pública. Estos largos años de silencio fueron sedimentando el humus, en el que luego fructifica, por revolucionario que fuese el cambio, el intelectual de los años cincuenta y sesenta.

Sólo teniendo en cuenta la que me gustaría llamar «larga etapa silenciosa» de Aranguren, cabe entender, una vez que toma conciencia de la «misión» del intelectual, los escritos y la actuación de la pública. Lo que entonces llamó la atención - y sigue llamándola treinta y tantos años más tarde- es la libertad con que salta a la «plazuela pública», para utilizar la expresión de Ortega, sin el menor temor, sin la menor mala conciencia. Aranguren entra en la vida española en los años cincuenta con lo que me atrevería a llamar una ingenuidad casi virginal, que se revelaria tan oportuna como fructifera.

Perteneciendo al bando de los vencedores, por origen social y sobre todo por su condición de católico - la catolicidad era a la sazón lo que daba el marchamo de hombre de bien-, no había intervenido en nada, ni había escrito nada que desde la izquierda o desde la derecha se le pudiera reprochar. Aranguren, en su generación y dentro de su grupo social, es de los pocos hombres públicos que no ha tenido que «descargar su conciencia» en uno u otro sentido, 
al haber permenecido callado durante los años trágicos de la vida española. Siendo en el fondo un «converso», parecía todo menos un «converso», al no existir un Aranguren público anterior con el que se le pudiera comparar. En la circunstancia particular de una España oficial que quería olvidar su pasado fascista, sin por ello arriesgarse a perder el poder si se volvía a las andadas, Aranguren tenía credibilidad, en cuanto lo que escribía y enseñaba era, por incómodo que pudicra parecer a los integristas de todos los bandos, «irreprochable».

Su planteamiento de que los verdaderos problemas estaban en la sociedad, más que en la «superestructura política», resultaba revolucionario, en cuanto acertaba en el diagnóstico - todavía está por hacer un cstudio detallado del tipo de sociedad que no sólo aguantó, sino que en buena parte apoyó la dictadura-, a la vez que profundamente conformista, al eliminar de su perspectiva lo único que de verdad no se podía hacer en la España de Franco, política partidaria, política concreta. «El contexto de la época, la presión de una censura agobiante, hacía imposible asumir una postura abiertamente crítica $\mathrm{cn}$ cl plano políticon ${ }^{36}$. Así era en efecto, los españoles teníamos que ser apolíticos por orden de la autoridad competente.

Las circunstancias - desde luego, la política, pcro también la intelectualimponían una crítica exclusivamente ética y sociológica. «Mi crítica del Sistema es intelectual, moral y sociológica», escribía Aranguren a la sazón. Sin duda acertado fue aprovechar hasta el último recoveco de las zonas grises permitidas para hacer la crítica ética y social del «sistema», máxime cuando estaba convencido de que en este plano hundían sus raíces los verdaderos males del país. Con muy buen sentido, Aranguren prefirió actuar tan sólo en los grupos sociales a los que tenía acceso: la juventud universitaria y el catolicismo más abierto y sensible. Lo que le critico, como tendremos ocasión de ver, no es que hiciese de la necesidad virtud, sino que elevara a norma general comportamiento tan prudente, Ilegando incluso a descalificar como intelectual al que, sin perjuicio de conservar su independencia, rompiese las reglas franquistas y se «metiese en política», que, en las condiciones impuestas por la dictadura, no podía ser más que «clandestina».

La labor crítica de Aranguren se vio facilitada por el hecho de haber empezado a actuar en los medios católicos, como «intelectual católico», especie desaparecida en España al dejar él, muy acorde con el espíritu de los tiempos, de encarnarla. Y aunque la Iglesia española de la época no estaba muy inclinada a la tolerancia $-y$ no hay peores insidias que las clericales, como muy bien tuvo ocasión de aprender, al sufrirlas en su propia carne-- la libertad que entonces se gozaba en los medios eclesiásticos era muy superior a la que se permitía en los políticos. Además, a mitad de los sesenta, el Concilio Vaticano II facilitó extraordinariamente las cosas al «heterodoxo» Aranguren.

Idem, p. 73 . 
Importa dejar constancia de que su aislamiento le libró de las dos «desviaciones» - la una en los años treinta; la segunda, en los cincuenta y sesentaque sufrieron los intelectuales coetáneos: en los treinta, la politización extrema, dando a la política un carácter absoluto que desembocó en el «totalitarismo»; en los cincuenta y sesenta, la toma de posiciones, mediatizadas por la «guerra fría». Considero mérito muy especial de Aranguren haberse librado de la politización extrema que se expandió como la cólera en los años treinta, entonces refugiado en la religión y la filosofía, así como en los cincuenta y sesenta, al saltar a la palestra pública, al haber denunciado a tiempo los déficits democráticos de las llamadas «democracias populares» y de las llamadas «democracias occidentales». Supo admirar lo mucho positivo de la sociedad nortcamericana, en particular su vigor intelectual y la calidad de algunas de sus universidades, sin caer por ello, todo lo contrario, en una idealización del american way of life. Supo también reconocer la importancia del marxismo para la comprensión de la sociedad contemporánea, sin ocultar las críticas más pertinentes, pese a las presiones sociales que denunciaban el menor distanciamiento crítico como expresión de un «reacionarismo» congénito. Su libro, El marxismo como moral, publicado en 1968, puede leerse todavía hoy con provecho. De pocos libros escritos en aquella fecha sobre el marxismo, o desde posiciones marxistas, puede decirse lo mismo.

Aranguren, como todo intelectual auténtico, reaccionó a su circunstancia, como acabamos de ver, configurado, modelado por las ideas y demás condicionamientos sociales con que se encontró en el tiempo que le tocó vivir, pero sin agotarse en ellos, sino conservando en todo momento un distanciamiento crítico. El intelectual, lo es, si trasciende al medio; su instrumento más específico, el pensar libre e independiente, consiste, precisamente, en este ejercicio de «ruptura" con todo aquello que se da por seguro en la sociedad en la que actúa.

Durante los dos últimos decenios del franquismo, esta posición crítica fue compartida de manera creciente por sectores cada vez más amplios de la sociedad española, en buena parte, incitada, despertada por la actividad intelectual dc Aranguren, hasta el punto de que los españoles terminaron por reconocerse en su pensamiento, de modo que sin quererlo, o mejor queriéndolo en lo más profundo de su ser, Aranguren se convirtió en la «conciencia de su pueblo». En los años sesenta y setenta su influencia fue muy considerable.

Con el advenimiento de la democracia, Aranguren no ha cambiado su actitud, permaneciendo fiel a sí mismo, al marcar de nuevo una distancia crítica con la realidad «establecida». Cuando el Poder se empeña en identificar el orden político «establecido» con la «democracia» sin más, Aranguren, contra viento y marea, insiste en los contenidos utópicos de la democracia, entendida como un proceso interminable, en el que en cada momento cabe contraponer lo que es, con lo que debe ser. «La democracia no es un status en el que pueda un pueblo cómodamente instalarse. Es una conquista ético-política de 
cada día que sólo a través de una autocrítica siempre vigilante puede mantenerse. Es más una aspiración que una posesión» ${ }^{37}$. Palabras escritas a comienzos de los sesenta y que ha sabido mantener en los setenta y los ochenta.

Aranguren ha mantenido su distanciamiento crítico y no ha tenido pelos en la lengua para decir en cada momento lo que había que decir. Ello no evita que, aunque entre la minoría más sensible a la dimensión ética de la política siga encontrando la audiencia de siempre, me temo que su voz, a diferencia de lo que ocurría en los años sesenta y setenta, en gran medida se pierda hoy en el desierto. El intelectual sigue cumpliendo con su función; lo que ha cambiado es la sociedad a la que dirige su mensaje, cada vez, en su aparente libertad, más controlada y sumisa, hasta el punto que se van cercenando paso a paso parcelas de libertad, sin que apenas lo note o se inmute.

Tales son los cambios ocurridos en la última década -incremento del bienestar y sobre todo de las perspectivas de conseguirlo, pese a que también hayan aumentado las desigualdades sociales y regionales; control sutil de los medios de comunicación, sobre todo los de mayor audiencia, radio y televisión; deterioro creciente de la vida universitaria y de los círculos intelectuales, con la desmoralización correspondiente- que algunos se preguntan dónde están los intelectuales, cuando éstos, como muestra patentemente Aranguren, están donde deben, lo que pasa es que se les nota menos, porque la sociedad ya no está dispuesta a recibir su mensaje.

El hecho es que nos encontramos ante una situación en la que indudablemente ha decrecido la demanda social del intelectual. Es un fenómeno que España comparte con las sociedades más desarrolladas de su entorno. Las razones son de orden muy distinto y tienen que ver con la mayor complejidad de la sociedad española, en la que, por un lado, un pluralismo de los valores, cada vez más marcado, y, por otro, una disolución social creciente que se corresponde con la anomía y fragmentación que caracteriza a la sociedad capitalista tardía, impiden pueda consolidarse otra voz que la que resulta del principio constitutivo del orden social establecido: la maximalización de los beneficios.

Si se escucha cada vez menos a los intelectuales, por mucho que se esfuercen en el cumplimiento de su "misión", el resultado es que poco a poco dejan de existir, ya que una sociedad receptora de su palabra es un ingrediente esencial para que pueda cuajar especie tan frágil. Hemos llegado a tal punto que los más cínicos, o más ingenuos, a veces es díficil distinguirlos, llegan a sostener la opinión de que en una sociedad abierta y socialmente equilibrada no habría ya lugar para moralistas ni generalistas, y que los únicos que podrán sobrevivir son los «expertos», es decir, los que hablan de lo que saben y dirigen su mensaje a los que compete.

No cabe duda que la sociedad española actual, a diferencia de la de los años veinte y treinta, o la de los años sesenta y setenta, deja mucho menos

\footnotetext{
${ }^{37}$ José Luis L. Aranguren, Ética y politica, Madrid, 1963, p. 188.
} 
espacio para la acción del intelectual en el sentido fuerte que le ha dado Aranguren. Una situación semejante tiene contenidos positivos - la gente es más libre y consciente y, por tanto, menos menesterosa de la palabra del intelectual- pero me temo que los factores verdaderamente operativos sean más bien negativos: la desmoralización general habría alcanzado tal extremo que, con la palabra libre, se hubiera evaporado la esperanza utópica.

\section{ESBOZO DE UNA CRÍTICA}

Para terminar, dos observaciones críticas, ya que la crítica, como con toda razón ha puesto énfasis Aranguren, es un elemento esencial de todo ejercicio intelectual y, en su modestia, estas consideraciones no han pretendido ser otra cosa. Las hago, sin embargo, con cierto temor, porque, como también con toda razón ha escrito Aranguren, «siempre, pero más aún cuando se hace crítica negativa, es menester extremar la precisión, el cuidado y la objetividad» ${ }^{38}$.

Mi primer punto de desacuerdo se refiere a los mismos supuestos filosóficos sobre los que Aranguren ha levantado construcción tan coherente como brillante. Después de que Ortega hubiese logrado romper con Kant — no es nada fácil-, marcando con ello el lugar desde el que hoy hay que hacer filosofía, Aranguren se ha apartado de su maestro para refugiarse de nuevo en la claridad inflexible de Kant. La separación contundente de la ética respecto de la política, de la política real, de la política que tiene que ver con el Poder -la otra, la sublimada, no es más que un aspecto de la ética-, tiene un sabor kantiano, de concepción «pura» de la ética como deber y convicción, que me parece que bloquea toda comprensión realista de la relación de la ética con la política real.

Porque el problema no se resuelve separando tajantemente un ámbito para la ética y otro para la política - la conexión entre la ética y la política es consustancial para ambas, hasta el punto que no logro entender qué sería una ética sin una dimensión política, como tampoco una política sin una dimensión ética-, en esto también estaría de acuerdo Aranguren. La diferencia radica èn que el problema no se resuelve, como él lo intenta, distinguiendo dos acepciones opucstas de la política, una, a la manera aristotélica, que se confunde con la ética, y otra, por así decir, perversa, que nada tendría que ver con la ética, y que hace coincidir con la concepción «moderna» de la política, como Poder.

La «demonización» del Poder, tentación en la que han caído no pocos para salvar la «buena conciencia», lejos de resolver el problema, bloquea, al contrario, el camino para encontrar el tipo de relación que ha de tener la ética con la política, pero con la política tal como es, en su conexión con el poder y en la lucha por el poder. Ello supone que necesitamos una concepción

\footnotetext{
* José Luis L. Aranguren, La ética de Ortega, Madrid, 1958, p. 40.
} 
de la ética -lamentablemente ni Aristóteles ni Kant sirven para llevar adelante esta empresa- en la que quepa establecer la relación consustancial de la ética con la política, tal como es en realidad. Buen weberiano, la he llamado ética de la responsabilidad, pero no oponiéndola a la de la convicción, sino tratando de fundamentarla en la convicción. Del mismo modo, una tcoría de la política en la modernidad no ha de oponer la «razón utópica»-la democracia es la gran utopía que ha creado Europa- a la "razón de Estado», sino que ha de esforzarse por vincular ambas tradiciones en una nueva concepción del «Estado democrático».

La segunda observación es más puntual, casi anecdótica, en cierto modo corolario de la anterior, pero, como tiene una cierta relevancia política, no quiero dejar de mencionarla. Nadie se sorprenderá si digo que no estoy nada de acuerdo con la desautorización que hace Aranguren de la participación política por los canales disponibles, partidos políticos o instituciones públicas. En bastantes textos de Aranguren se puede leer entre líneas una descalificación implícita de la militancia partidaria, como si fuera incompatible con la función del intelectual. Aranguren nos pone en la tesitura de tener que elegir entre la vocación intelectual o la vocación política, ya que ambas serían irreconciliables: o se es intelectual, o se es político; o se tiene la palabra, o se tiene el poder. Ahora bien, como él mismo escribió en su día, la relación puede ser, y de hecho es, dramáticamente tensa, pero no trágicamente incompatible.

En el plano teórico en que nos movemos no cuentan las disculpas personales - falta de gusto o de aptitudes para la política - ni las razones de oportunidad o de eficacia, como por ejemplo, que en el contexto del franquismo y a partir de su particular situación personal hubiese sido mucho más útil para los objetivos políticos de la sociedad española el que se hubiera mantenido al margen de la política clandestina. Yo, al menos, también así lo creo y, por tanto, me felicito de que Aranguren hubiera escogido el mejor camino. La cuestión se plantea exclusivamente en cuanto principio general, y aquí no cabe la menor duda de que Aranguren deduce de una comprensión "pura» de la ética la incompatibilidad del intelectual para intervenir directamente en política.

Pero justamente éste es el argumento de fondo que acabamos de poner en tela de juicio, al subrayar la necesidad de una ética nada «pura», sino tan «enraizada» como «circunstancial», capaz de vincular con la política, no sólo al intelectual, sino a toda persona libre que, en cuanto tal, sólo pueda serlo si participa en las instituciones políticas de la sociedad a la que pertenece. El concepto de libertad es ético y político a la vez. Idea que tenía muy clara el antiguo ciudadano de la polis, y que volvió a surgir con la presunción, en su origen rousseauniana, de que la eliminación de la «alienación» suponía superar la distinción entre homme y citoyen.

En las estructuras políticas de la sociedad contemporánea, a nadie se le oculta lo difícil que resulta aspirar a ser, de la mejor forma posible, ciudadano libre de pleno derecho, participando activamente en las organizaciones e ins- 
tituciones políticas, sin por ello hipotecar la libertad, antes al contrario, ampliando la personal y la social. Pero las dificultades realmente existentes no deben servir de pretexto para aceptar sin más la perversión cada vez más extendida -śsta sí que es una perversión enajenante- de que el ámbito de la política, partidaria e institucional, habría que dejarlo reservado exclusivamente para los «políticos profesionales», de los que cualquier hombre honrado que quiera perservar su libertad - afán que, en ningún caso, es exclusivo del intelectualdebería mantenerse apartado.

Para justificar su apartamiento de los partidos, Aranguren añade un segundo argumento, éste ya exclusivamente sociológico, de sociología política, que me parece de mucho mayor peso. Aranguren, que como ya hemos dicho estudió como sociólogo la juventud de los sesenta y prestó detenida atención al «movimiento estudiantil» de aquellos años, percibió muy perspicazmente que los 'viejos partidos históricos, mastodontes burocratizados, probablemente servirían cada vez menos para plantear, y a mayor abundancia, para resolver los problemas más acuciantes de nuestras sociedades. La experiencia de estos últimos años -y no sólo en España- no ha hecho más que confirmar esta sospecha.

Que haya que inventar «nuevas formas, diferentes de los partidos históricos y nuevas estrategias» -el hacer histórico consiste, precisamente, en ir inventando nuevas instituciones-- no conlleva que haya que desinteresarse por las existentes, al menos mientras no dispongamos de relevo. Ocurre que Aranguren, como tantos otros ciudadanos - aunque él sea probablemente pionero en este campo-, no pudo en el franquismo, ni puede hoy en una democracia establecida, identificarse con ninguno de los partidos cxistentes - no en vano ya vivió la crítica a los partidos de la preguerra-y con toda razón reclama otras formas de participación política. Es ésta una cuestión clave que se plantea por doquier en las «democracias occidentales». Ahora bien, mientras la alternativa real sea «democracia de los partidos», con todas sus deficiencias, o dictadura pura y simple, habrá que andarse con mucho cuidado antes de caer en una descalificación global de los partidos, como de hecho subyace si se da por supuesto que la militancia partidaria sea incompatible con la libertad del ciudadano, lo que, de ser así, los haría esencialmente nocivos. Lo mismo se ha dicho de las Iglesias - icómo ser libre en una sociedad tan cerrada?y él bien sabe que, siendo muy real este peligro, se puede conservar, $y$ aun aumentar, la libertad en una comunidad religiosa; y ¿por qué esto no seria también posible en una política? La forma como el intelectual Aranguren pertenece a la Iglesia sin perder su libertad puede servir de pauta al intelectual para actuar en los partidos: como heterodoxo en la base. 